UNIVERSUM • Vol. 2 • No 29 • 2014 • Universidad de Talca

Intelectualidad indígena en América Latina: Debates de descolonización, 1980-2010

Pedro Canales Tapia

Pp. 49 a 64

\title{
INTELECTUALIDAD INDÍGENA EN AMÉRICA LATINA: DEBATES DE DESCOLONIALIZACION, 1980-2010
}

\author{
Indigenous intellectuals in Latin America: Discussion of decolonialization \\ Pedro Canales Tapia*
}

\section{RESUMEN}

El siguiente trabajo describe la emergencia de una vertiente de intelectuales indígenas en América Latina, marcada por reflexiones cruzadas por la descolonización como eje teórico, y la producción de conocimiento social que estos sujetos han ido articulando en los últimos treinta años. En este sentido, podemos consignar como propósito central de esta mirada analítica, develar el debate étnico en contextos nacionales, toda vez que esta región ha experimentado fuertes transformaciones en las esferas estatales y de la sociedad civil; de este modo, en estas líneas se fijan posiciones y perspectivas de trabajo en el seno de la intelectualidad indígena en general.

Palabras clave: Intelectuales indígenas, descolonización, debate étnico, producción de conocimiento.

\begin{abstract}
The following paper describes the emergence of an aspect of indigenous intellectuals in Latin America, marked by reflections decoloniality crossed by the theoretical axis, and the production of social knowledge that these subjects have been articulated in the past thirty years. In this sense, we can consign central purpose of this analytical perspective, ethnic debate unveil national contexts, since this region has undergone major transformations in the areas of state and civil society in this way, in these lines are set working positions and perspectives within indigenous intellectuals in general.
\end{abstract}

Keywords: Indigenous Intellectuals, descoloniality, race debate, production of knowledge.

\footnotetext{
${ }^{1}$ Artículo realizado en el marco del Proyecto No 11121231 del Fondo Nacional de Desarrollo Científico y Tecnológico (FONDECYT de iniciación), titulado: “Pensamiento en Intelectuales indígenas en América Latina, 1980-2010".

*Instituto de Estudios Avanzados, Universidad de Santiago de Chile. Santiago, Chile. Correo electrónico: pedro.canales@usach.cl Artículo recibido el 20 de agosto de 2012. Aceptado el 28 de octubre de 2013.
} 


\section{INTRODUCCIÓN}

Reflexionar acerca de las intelectualidades indígenas en América Latina, implica estudiar un proceso de larga data en la lucha indígena por reconocimiento y visibilización de su cultura, territorios y demandas sociales y políticas, según estudios/as como ÁlvarezMonroy, Fernández, Rappaport y Zapata ${ }^{2}$. Es también una historia que conjuga traumas, exclusión y abusos de parte de la sociedad dominante -colonizadora con estricto rigorhacia aquellos indígenas que se atrevieron a ingresar al sitio más genuinamente occidentak en esta región del mundo: la academia ${ }^{3}$.

Ahora bien, los estudios sociales tanto de intelectuales indígenas como no indígenas, dan cuenta en los últimos lustros de una situación interesante de destacar: la emergencia indígena, reetnificación o indianización de población indígena, que por efectos de la colonización y el peso de su poder parecieron desaparecer de la faz de la Tierra ${ }^{4}$. Sin duda que este antecedente es gravitante, toda vez que a partir de este proceso se observa una censura cualitativa entre indígenas letrados de décadas anteriores a los años 80 y los posteriores. En este sentido, no resulta extraño plantear como eje definitorio de la diferenciación, lo que podríamos denominar propuesta descolonialista entre los intelectuales indígenas de la historia reciente de América Latina, cuestión que se acerca a lo que Jorge Viaña denomina interculturalidad emancipatoria $a^{5}$ y que tiene que ver con estudiar la sociedad para redefinir sus códigos y lineamientos, dejando atrás la fórmula que eterniza el estatus quo colonialista, propagada por las disciplinas científicas contemporáneas de corte occidental colonial. Digamos en este sentido, que la descolonización en la teoría y la praxis ha sido un proceso paulatino pero sostenido de reflexión pero sostenido en el tiempo, de debate e investigación, que apuntan hacia nuevas matrices societarias. Walter Mingolo por ejemplo, ha planteado que este constructo es punta de flecha de una nueva discusión teórica y epistemológica, que tiene con meta elaborar nuevas estructuras de interpretación, análisis y relaciones sociales de la realidad, desde ópticas que no tengan nada que ver con la clásica y hegemónica dinámica colonizador-colonizado.

En este contexto, podemos distinguir -como lo plantea Álvaro Bello-intelectuales indígenas tradicionales y contemporáneos ${ }^{6}$. Dentro del segundo grupo, encontramos a los primeros intelectuales indígenas, como planteamos anteriormente, descolonizados, los cuales comenzaron a dar sus primeros pasos en la academia y sus espacios contiguos, desde

\footnotetext{
${ }^{2} \mathrm{Al}$ respecto proponemos cuatro textos para esta discusión: Silvia Monroy-Álvarez "Sobre intelectuales y activistas indígenas: Dos trayectorias interculturales posibles", Universitas humanistica 66, 2008; Blanca Fernández. "¿Quiénes son los intelectuales indígenas ecuatorianos? Aportes para la construcción intercultural de saberes en América Latina”, A Parte Rei. Revista de Filosofia 71, 2010; Joanne Rappaport. "Intelectuales públicos indígenas en América latina: Una aproximación comparativa", Revista Iberoamericana 220, 2007; Claudia Zapata (Comp.), Intelectuales indígenas piensan América Latina. Serie Tinkuy No 2, Universidad Andina Simón Bolívar - Centro de Estudios Culturales Latinoamericanos de la Universidad de Chile - Editorial Abya Yala, Quito, 2007. ${ }^{3}$ Ver Marimán, Pablo. "Formación de intelectuales indígenas: ¿El rol de la educación superior?” Ponencia presentada en Congreso Internacional "Equidad, Interculturalidad y Educación superior". Chile, Temuco, 2011.

${ }^{4}$ Bengoa, José. Emergencia indígena en América Latina. Santiago de Chile: Fondo de Cultura Económica, (1999): 15.

${ }^{5}$ Viaña, Jorge. La interculturalidad como herramienta de emancipación. La Paz, Bolivia: Instituto internacional de integración. Convenio Andrés Bello, (2009): 20.

${ }^{6}$ Ver Bello, Álvaro."Intelectuales indígenas y universidad en Chile: conocimiento, diferencia y poder entre los mapuche en Robert Austin”. En Robert Austin (Ed.), Intelectuales y Educación Superior en Chile: De la Independencia a la Transición Democrática 1810-2001. Santiago de Chile: Editorial CESOC, 2004.
} 
la tensión y la conflictualidad, desde los movimientos étnicos, según Claudia Zapata ${ }^{7}$, remeciendo con su presencia la ortodoxia letrada occidental en suelo latinoamericano. Por medio de la letra no indígena, esta intelectualidad ingresó al ruedo de las ideas, del debate y la discusión en foros nacionales e internacionales ${ }^{8}$. La voz indígena, así, asumió un nuevo estatus, una nueva impronta; cada vez más urbana y empapada de los códigos "del otro" para interpelarlo. Del "yo" individual se comenzó a transitar al "nosotros" comunitario", verdadero cuestionamiento cognitivo a la estructura cientificista cartesiana, objetivista a ultranza, rígida en todo momento y lugar, vigente aun hoy en las universidades de la región, ingresando además al ruedo de la historia intelectual, de la cual Rama, Altamirano, Devés, Di Pascuale y Alburquerque, entre otros, escriben para delimitar las fronteras, trincheras y desafíos de la intelectualidad latinoamericana ${ }^{10}$. De esta forma, la siguiente proposición postula que existe un vínculo inmediato entre coyuntural social y política, protagonizadas por los movimientos indígenas regionales y el debate en gestación entre la intelectualidad étnica decolonizada, lo cual a redundado en la activación de flujos dinámicos, constantes y redefinitorios de la discusión relativa al presente y futuro de los pueblos indígenas en su conjunto. Dicho de otra manera, la intelectualidad indígena es considerada como soporte informacional y dialógico en proceso de visibilización permanente y en plena conjunción con los movimientos indígenas, marcando así el "ser" y "deber ser" entre los movimientos, pueblos y nacionalidades en contextos globalizados, altamente homogenizadores y asimilacionistas. Por último, consignemos que la literalidad de esta presentación, ha sido pensada en el desglose de las fuentes y el debate, a partir de décadas de reflexión, discusión, charlas y foros de los y las intelectuales indígenas; de esta forma nos podemos situar históricamente en escenarios marcados por el accionar de los Estados y las sociedades hegemónicas, para luego detener la mirada en las propuesta de sentido y la discursividad de estos sujetos etnoletrados, de cara a sus ideas de mundo, sociedad y comunidad.

\section{LA “DÉCADA GERMINAL” PARA LOS PUEBLOS INDÍGENAS}

La década de 1980 para América Latina es conocida como la "década perdida", puntualmente por las paupérrimas tasas de crecimiento económico y la elevada deuda externa registrada por los países de la región ${ }^{11}$. El modelo neoliberal impuesto en estos años, no alcanzó el anhelado progreso, como indicaban sus defensores, sino que agudizó los índices de pobreza en el más amplio sentido de la palabra.

Ahora bien, ¿Cuáles fueron los debates más destacados para los pueblos indígenas y sus respectivos movimientos durante estos años? En líneas gruesas, durante la década de

\footnotetext{
${ }^{7}$ Zapata, Claudia. Intelectuales... op. cit., 9.

${ }^{8}$ Ver Rama, Ángel. La ciudad letrada. Santiago de Chile: Tajamar Ediciones, 2004.

${ }^{9}$ Zapata, Claudia. Intelectuales... op. cit.

${ }^{10}$ Ver Rama, Ángel, op. cit.; Altamirano, Carlos. Historia de los intelectuales en América Latina. Argentina: Katz Editores, 2008; Devés, Eduardo. Carta a la intelectualidad. Santiago de Chile: Grafitti Editores, 2007; Di Pascuale, Mariano. "De la historia de las ideas a la nueva historia intelectual: Retrospectivas y perspectivas. Un mapeo de la cuestión”, Universum. Revista de Humanidades y Ciencias Sociales 26/1, 2011; Alburquerque, Germán. "La trinchera letrada. Ideas, acción y poder del intelectual latinoamericano en la Guerra Fría”. Tesis doctoral. Santiago de Chile: Pontificia Universidad Católica de Chile, 2009.

${ }^{11}$ Para esta discusión ver: Ocampo, Juan Antonio. América Latina y el Caribe. CEPAL, 2005; French-Davis, Ricardo. Reformas para América Latina. Después del fundamentalismo Neoliberal. Argentina: CEPAL - Siglo XXI Editores, (2005): $22-23$.
} 
1980, los grandes temas que preocuparon a los movimientos indígenas -la intelectualidad indígena se encontraba en proceso de visibilización- fueron aquellos referidos a la defensa y promoción de los derechos humanos indígenas y la consiguiente denuncia a su violación. Recordemos que este lapso está cruzado por las fases finales de las dictaduras militares y las guerras civiles en varios países con considerables porcentajes de población indígena.

De acuerdo a los expertos en estos temas y la literatura disponible, en estos años se comienzan a erigir movimientos indígenas regional en contextos autoritarios o en vías de transición política ${ }^{12}$, poderosos a la luz de procesos de reetnificación registrados en las grandes ciudades latinoamericana ¿Cómo en un escenario tan magro para los pueblos y nacionalidades indígenas, y comunidad en general, se fue gestando un potente y propositivo movimiento étnico continental? Cabe destacar en este orden argumental, las reuniones o conferencias de Barbados llevadas a cabo en los años 70, como grandes propulsoras de la realidad étnica de los años 80 , cada vez más lejanas del indigenismo institucional, propio de décadas pretéritas ¿Qué indicaron estas reuniones y cuál fue el procesamiento dado por la intelectualidad en cuestión, de la época a las conclusiones de estas reuniones? La primera conferencia desarrollada en enero de 1971 indicó entre otros puntos, los siguientes: "Los indígenas de América continúan sujetos a una relación colonial de dominio que tuvo su origen en el momento de la conquista y que no se ha roto en el seno de las sociedades nacionales", además de consignar que "La estructura interna de nuestros países dependientes los lleva a actuar en forma colonialista en su relación con las poblaciones indígenas", apuntando al Estado y sus políticas indigenistas como responsable directa de esta situación, pues "[...] la política indigenista de los estados nacionales latinoamericanos ha fracasado tanto por acción como por omisión"13.

Por su parte, la segunda conferencia llevada a cabo el año 1977 comienza saludando a los "hermanos indios", para luego sostener que "En América los indios estamos sujetos a una dominación que tiene dos caras: la dominación física y la dominación cultural”, las primera es de corte económico y se refiere al despojo de la tierra, y la segunda tiene que ver con la noción de que sólo la cultura occidental "tiene valor" en el mundo actual. Junto a lo interior, esta segunda declaración identifica tres grupos de población indígena: los que viven aislados y posee sus códigos étnicos intactos, los que mantienen la cultura pero en contextos de dominación y los desindianizados ${ }^{14}$, concluyendo con la presentación de un gran objetivo a seguir:

Conseguir la unidad de la población india, considerando que para alcanzar esta unidad el elemento básico es la ubicación histórica y territorial en relación con las estructuras sociales y el régimen de los estados nacionales, en tanto se está participando total o parcialmente en estas estructuras ${ }^{15}$.

De esta forma, la situación política entre los pueblos indígenas comenzó a irradiar paulatinamente confianza y amparo en declaraciones como éstas; las cuales fueron un

\footnotetext{
${ }^{12}$ Algunos textos que trabajan este tema son: Assies, Willem y Gundermann, Hans (Edit.), Movimientos indígenas y gobiernos locales en América Latina. San Pedro de Atacama: Línea Editorial IIAM - Universidad Católica del Norte, (2007): 7; Bengoa, José. Emergencia indígena en América Latina. Santiago de Chile: Fondo de Cultura Económica, (2000): 11; Martí, Salvador. Sobre la emergencia e impacto de los movimientos indígenas en las arenas politicas de América Latina. Barcelona: CIDOB, (2004): 36.

${ }^{13}$ Primera declaración de Barbados, enero 1971, p. 1.

${ }^{14}$ Ibid.

${ }^{15}$ Ibid.
} 
continuo que permitió la eclosión de debate y figuras intelectuales descolonizadoras, tales como Silvia Rivera Cusicanqui en Bolivia, fundadora junto a otros intelectuales del Taller de historia oral andina en 1983, "[...] una de las iniciativas más importantes en el proceso de recuperación de la memoria de las luchas indígenas por el territorio y la identidad aymara" ${ }^{16}$.

Ahora bien, consignemos a partir del influjo de Barbados, que el año 1979 los Mapuche en Chile iniciaron un difícil proceso de rearticulación del movimiento indígena en escenarios de dictadura militar y decretos de ley que terminaban con la propiedad indígena y sus habitantes ${ }^{17}$. Lo anterior activó el debate con urgencia y visibilizó a intelectuales mapuche de corte descolonizadores ¿Qué significó esto? Principalmente, si observamos la lógica de las organizaciones indígenas, que los intelectuales indígenas cada vez más se fueron alejando de ethos modernizadores occidentalistas a la hora de interpretar la realidad circundante, para comenzar a resaltar y proponer vías de desarrollo y sociabilidad desde lo propio, desde lo indígena ${ }^{18}$.

Así por ejemplo, a nivel latinoamericano durante esta década destacó una fuerte presencia de publicaciones indígenas, concentradas en núcleos temáticos tales como lingüística, historia y rescate cultural. Respecto del primer núcleo, encontramos en 1980 el trabajo de Víctor de la Cruz, en México, referido a canciones zapotecas de la zona de Tehuentepec ${ }^{19}$; en 1982, también de autoría de Víctor de la Cruz registramos el trabajo titulado Di idxa 'Sti' Pancho Nácar, también en 1980 Luis Macas comienza un trabajo de rescate y sistematización de las lenguas indígenas en Ecuador ${ }^{20}$; el año 1982 en Chile, Anselmo Raquileo publica en el boletín informativo de desarrollo y cambio de CAPIDE un artículo denominado El alfabeto mapuche, el cual complementa en 1985 con dos nuevos trabajos referidos a la construcción analítica y sistemática en el idioma mapuche o mapudungun, y otro titulado Tres modos de hablar en mapudugun"21. También en Chile, Maria Catrileo, en 1984, presenta a la discusión académica el texto Consideraciones lingüísticas en torno al grafemario uniforme para el mapudugun"22. Por último, Pedro Humire en 1986 dedicó sus esfuerzos a estudiar la situación de la lengua aymara en el norte de Chile, toda vez que este sistema de códigos lingüísticos y simbólicos que encontraba en una profunda crisis de vigencia, según el autor ${ }^{23}$.

\footnotetext{
${ }^{16}$ Entrevista a la socióloga Silvia Rivera: "Evo Morales se ha visto con su límite. Se acabó la luna de miel” (24-05-2011). Disponible en:http://losmovimientoscontraatacan.wordpress.com/2011/05/24/silvia-rivera-\%e2\%80\%9cevo-morales- seha-visto-con-su-limite-se-acabo-la-luna-de-miel\%e2\%80\%9d/ [Consultado el: 31 de julio de 2012].

${ }^{17}$ Canales, Pedro. "Impronta 79", Revista Pentukun 3. IEI. UFRO, (1998): 31; Aylwin, José. Materializaciones y conflictos. Temuco: Instituto de Estudios Indígenas - Universidad de la Frontera, 2000.

${ }^{18}$ Textos como j...Escucha, winka...! de Pablo Marimán, Sergio Caniuqueo, José Millalén y Rodrigo Levil, publicado en 2006 por Editorial LOM, es un claro ejemplo de esta actitud intelectual.

19 Textos De La Cruz, Víctor. "La escritura contemporánea del zapoteca del Istmo". En Zapata, Claudia (Comp.), Intelectuales... op. cit.

${ }^{20}$ Algunos trabajos de Luis Macas en los años 80: Cartillas 1, 2, 3 de Alfabetización de Adultos "Núucanchi Shimi", Publicación de la Pontificia Universidad Católica del Ecuador y del Ministerio de Educación y Cultura, 1980; Metodología de Enseñanza para maestros. Quito: Pontificia Universidad Católica del Ecuador, 1982 y Experiencias de Educación Bilingüe de América Latina. Publicado en México por el Instituto Indigenista Interamericano y la UNESCO, 1984.

${ }^{21}$ Raguileo, Anselmo. "El alfabeto mapuche", Boletín informativo desarrollo y cambio № 2. Temuco: CAPIDE, 1982; Raguileo, Anselmo. "Tres modos de hablar el Mapudungun", Boletín informativo desarrollo y cambio № 14. Temuco: CAPIDE, 1985 y "Construcción analítica y construcción sistemática en el Mapudungun”, Boletín informativo desarrollo y cambio № 16. Temuco: CAPIDE, 1985.

${ }^{22}$ Ver por ejemplo Catrileo, María. "Consideraciones lingüísticas en torno a un grafemario uniforme para el mapudungun", Actas de Lengua y Literatura 1. Temuco: UFRO, 1995.

${ }^{23}$ Humire, Pedro. "Influencia de la cultura occidental en la desaparición de la lengua aymara en el norte de Chile", Antropología histórica. Etnología contemporánea. Anales de la reunión anual de etnología. Tomo 1. La paz, Bolivia: USEF, 1986.
} 
En cuanto a los estudios históricos y rescate cultural entre la intelectualidad indígena durante los años 80, las actas del Taller cultural Causanacuchic de Ecuador, centradas en rescatar testimonios Otavalo ${ }^{24}$, fueron uno de los primeros esfuerzos al respecto, junto al Taller de historia oral andina fundado en Bolivia, como se consignó en páginas anteriores por Silvia Rivera Cusicanqui; así también durante estos ańos destacó el trabajo de Estelina Quinatoa, también en tierras ecuatorianas, con investigaciones dedicadas al rescate de la textileria indígena como expresión de autenticidad étnica ${ }^{25}$. Por otro lado, respecto del ethos tribal entre las comunidades de la sierra peruana, Lorenzo Huerta, escribió sobre de las tribus Ancku Wallof, como expresión de pervivencia social-cultural, mientras en Chile una agrupación de jóvenes adscritos a Ad Mapu llevaban a cabo por primera vez la teatralización del We Tripantü o año nuevo mapuche ${ }^{26}$. Por último, cabe destacar el trabajo del historiador Roberto Choque referido a la masacre de Jesús de Machaca, acaecida en marzo de 1921, contra las comunidades altiplánicas, en rebeldía contra los abusos del corregidor Estrada ${ }^{27}$. Cierra la década de 1980, la declaración de la CONAIE en Ecuador y el Pacto de Nueva Imperial en Chile. La primera, referida a las nacionalidades indígenas en este país y el proceso de organización que han ido experimentando en los últimos años ${ }^{28}$, y la segunda, vinculada al apoyo político indígena al candidato de las fuerzas democráticas, contra el candidato continuista ${ }^{29}$. Sin duda que estos hitos serán el aviso de la historia que vendrá para los pueblos indígenas y los movimientos étnicos latinoamericanos.

\section{LA “DÉCADA GANADA” PARA LA MOVILIZACIÓN}

Varios autores latinoamericanos se han referido a los años 90 en términos étnicos, como la "década ganada" - es el caso de Luis Macas y Pablo Dávalos en Ecuador-definiendo estos lustros como el período histórico en el cual los pueblos indígenas y sus respectivos movimientos étnicos, asumieron preponderancia y peso específico como actores sociales y políticos en el seno de los países en los cuales se desenvuelven, como pueblos colonizados ${ }^{30}$.

Estos años estuvieron marcados por varios aspectos. Uno de ellos fue el emergente proceso de redemocratización vivido por los Estados controlados en décadas anteriores por mano militaris ${ }^{31}$. Otro punto que marcó las agendas y el debate fue la conmemoración por parte de Espańa y los Estados locales de los 500 ańos del arribo del otrora imperio hispánico a tierras americanas o como indican los kunas, a Abya Yala ${ }^{32}$. Por último, un

\footnotetext{
${ }^{24}$ Taller cultural Causanacuchi. Testimonios Otavalos, 1980.

${ }^{25}$ Quinatoa, Estelina. Textiles de Alejandro Quinatoa. Catálogo de exposición. Quito: Banco Central del Ecuador - OEA.

${ }^{26}$ AD Mapu: organización mapuche ligada al Partido Comunista / We Tripantü: celebración indígena coincidente con el solsticio de invierno. Este último dato entregado por el historiador José Marimán en Charla referida a este tema, efectuada en el Instituto de Estudios Avanzados de la Universidad de Santiago de Chile (USACH), el 14 de junio 2012.

${ }^{27}$ Ver Choque, Roberto. La masacre de Jesús de Machaca. Bolivia: Ediciones Chitakolla, 1986.

${ }^{28}$ CONAIE. Las nacionalidades indigenas en el Ecuador. Nuestro proceso organizativo. Quito: Ediciones Abya Yala, 1989.

${ }^{29}$ Pacto Nueva Imperial en Bengoa, José. Historia de un conflicto: El estado y los mapuches en el siglo XX. Santiago de Chile: Editorial Planeta, (1999): 183-215.

${ }^{30}$ Dávalos, Pablo. "Movimiento indígena en América Latina: el derecho de la palabra”. En Pablo Dávalos (comp.), Pueblos Indígenas, Estados y Democracia. Argentina: CLACSO, 2005.

${ }^{31}$ Martí, Salvador. Sobre la emergencia ...op. cit.

${ }^{32}$ Bengoa, José. Historia de un conflicto...op. cit., 17.
} 
tercer hito, de la mano con el primero, fue el sistemático proceso de profundización del modelo neoliberal en las economías nacionales. Sin duda que todos estos eventos, revisten en sí mismos, altos grados de complejidad, tensión y controversia ${ }^{33}$. Considerando este escenario de acción y movilización ¿Qué produjeron los y las intelectuales indígenas en la región durante esta década? Si advertimos que la emergencia indígena de la que hablan José Bengoa, Pablo Dávalos, Willen y Gundermann entre otros ${ }^{34}$, se explayó en un contexto de cuestionamiento al modelo neoliberal, un creciente y sostenido proceso de globalización de la información, el poder y el mercado, y el fortalecimiento de una diversidad de movimientos sociales locales y planetarios, la intelectualidad indígena enfocó su trabajo en ámbitos como los siguientes: la definición y articulación de sociedades pluriculturales y multiétnicas desde el accionar de los movimientos indígenas, el derecho a la autonomía indígena en el seno de los Estados nacionales, y la noción de interculturalidad como pieza vital para romper el colonialismo y asumir una nueva etapa en la historia indígena y no indígena de América Latina; a esto debemos agregar el creciente interés por dilucidar las claves que hicieron del movimiento indígena de los años 90 un actor social relevante.

Detengamos el análisis en el debate y producción efectivamente publicada por la intelectualidad indígena durante esta década. Los estudios lingüísticos, en este sentido, tuvieron durante estos ańos gran relevancia, toda vez que la academia estipula como requisito indispensable en la pervivencia étnica, el uso de la lengua materna. Veamos.

En 1990 en Perú, Juan José García presentó un trabajo de rescate referido a Huamanga en los cantos de arrieros y viajantes; en 1995, por su parte, Elisa Loncón escribe un artículo en el cual llamaba a las autoridades y todos los involucrados en el tema a impulsar una nueva política del lenguaje en Chile ${ }^{35}$; ese mismo año Maria Catrileo presenta una propuesta conceptual y formas para la cuantificación del mapuzungun ${ }^{36}$.

Por otro lado, el rescate de la sabiduría indígena y su historia propia o vinculada con entidades tales como los Estados nacionales, fueron uno de los aspectos centrales en este debate. En este sentido, en 1990 en Chile el Centro de estudios y documentación mapuche Liwen abrió los fuegos publicando un artículo para la discusión, centrado en la relación pueblo mapuche-Estado nacional, a lo que se agregó la noción de autonomía regional como nuevo aporte al foro ${ }^{37}$. Al año siguiente, Carlos Mamani desde Bolivia escribía Taraqu 1866-1930, un relato histórico concerniente a masacres, guerras y revolución indígena. El año 93 los ya citados Talleres de historia oral andina se comprometían en labores políticas al presentar desde su seno los estatutos de la federación de ayllus de la provincia Ingaví. En México, por otro lado, Juan José García presentó en 1996 una reflexión sobre la racionalidad de la cosmovisión andina ${ }^{38}$; en 1997 Cornelio Chipana presentó un trabajo referido a los indígenas y las Universidades, en el cual devela mitos y

\footnotetext{
${ }^{33}$ French-Davis, Ricardo. La reforma ... op. cit.; Gómez Leyton, Juan Carlos. Chile Neoliberal. Editorial Universidad ARCIS - CLACSO Ediciones, (2010): 14.

${ }^{34}$ Bengoa, José. Emergencia...op. cit.; Assies, Willen y Gundermann, Hans. Movimientos... op. cit. y Dávalos, Pablo. "Movimiento indígena..."op. cit.

${ }^{35}$ Loncón, Elisa. Por una nueva politica del lenguaje. Temas y estrategias del desarrollo lingüistico del mapudungun. Temuco, chile: Pehuén - UFRO, (1995): 12-13.

${ }^{36}$ Catrileo, María. "Conceptos y formas de cuantificación en el mapudungun", Revista de Lingüistica Teórica y Aplicada 23. Concepción, Chile: Universidad de Concepción, 1995.

${ }^{37}$ CEDM Liwen. Revista Liwen No 1 . Temuco.

${ }^{38}$ García, Juan José. "La etnonarrativa andina”. En Claudia Zapata (Comp.), Intelectuales... Op. cit.
} 
otras tensiones ${ }^{39}$. Cerrando en 1999 esta serie de propuestas argumentativas María Teresa Panchillo y Ximena Ancamil con un texto sugestivo, que llamaba a los pueblos indígenas "que nuestra vida continué" 40 .

Por último, consignemos que la discusión en torno a los proceso de lucha y resistencia étnica al dominio colonial, en su versión imperial y/o republicana, fue otro de los debates en los cuales participaron los intelectuales indígenas de la región. En este punto cabe destacar la fuerte presencia de intelectuales mapuche en estos focos dialógicos -marcado por el trabajo del Centro de Estudios y Documentación Mapuche Liwen fundado en 1989 en Temuco-, en gran medida impulsados por el proceso de redemocratización que Chile comenzó a vivir iniciada la década de los 90, más aun luego del pacto entre quien fuera candidato presidencial de las fuerzas democráticas, a la postre presidente, Patricio Aylwin, y las organizaciones indígenas ${ }^{41}$.

Citemos algunos ejemplos. En 1990 José Marimán escribía el primer documento relativo a la viabilidad de tener en Chile autonomía regional; ese mismo año Pedro Marimán se refería al voto político mapuche como expresión de una tendencia compleja entre los miembros de este pueblo y la esfera política dominante; en 1994 José Ankań marcó el inicio de una nueva vertientes de estudio sobre de los mapuche, al referirse a los mapuche urbanos como nueva expresión de etnicidad compleja y resistencial ${ }^{42}$. En 1997 tres textos concentran su atención en la discusión sobre la autonomía regional, el movimiento social mapuche y los procesos de emigración campo-ciudad de los mapuche en el siglo XX, proceso denominado "diáspora mapuche" ${ }^{33}$. Finalizando esta década con el escrito de José Ankañ y Margarita Calfío, titulado El retorno al país mapuche, en el cual se vuelve a considerar temáticas como la diáspora, la autonomía y el poder de la organización étnica desde sitiales de descolonización ${ }^{44}$.

\section{DÉCADA DE EVALUACIÓN Y NUEVOS CAMINOS}

La década del 2000 podríamos decir, parafraseando a Manuel Castells y Ulrick Beck, es la época netamente de la información, el riesgo, las redes sociales y el conocimiento ${ }^{45}$. Para el caso de América Latina, Fernando Calderón se pregunta si es posible referirse a globalización en este continente, marcado por altas tasas de inequidad, pobreza y desigualdad ${ }^{46}$; mientras Néstor García Canclini define a sus habitantes -sujetos que han experimentado grandes

\footnotetext{
${ }^{39}$ Chipana, Cornelio. "La universidad y los pueblos indígenas, mito y realidad". En José Aylwin (Edit.), Universidad y pueblos indígenas. Temuco, Chile: Instituto de Estudios Indígenas, Universidad de la Frontera, 1997.

${ }^{40}$ Panchillo, María Teresa y Ancamil, Ximena. Amulepe tayiñ mogen: Que nuestra vida continué. Comité de solidaridad catalán. Temuco, Chile. S/F/E.

${ }^{41}$ Pacto de Nueva Imperial, ver en Bengoa, José. Historia de un conflicto... op. cit., 184.

${ }^{42}$ Ankań, José. "Los urbanos: Un nuevo sector dentro de la sociedad mapuche contemporánea”, Pentukun 1. Temuco, Chile: Instituto de Estudios Indígenas, Universidad de la Frontera, 1994.

${ }^{43}$ José Marimán, Pedro Marimán y Margarita Calfío han investigado la historia mapuche, en cuento a proceso de migración campo-ciudad, acaecidos en Chile, con fuerza y de forma sostenida desde la década de 1930 en adelante.

${ }^{44}$ Ankañ, José y Calfío, Margarita. "El retorno al país Mapuche", Revista Liwen 5. CEDM Liwen. Temuco, Chile, 1999.

${ }^{45}$ Ver Castells, Manuel. La era de la información. Economía, sociedad y politica. El poder de la identidad. Vol. II. México: Siglo XXI Editores, (2002): 25 y Beck, Ulrich. La sociedad del riesgo. Hacia una nueva modernidad. Barcelona: Editorial Paidós, (1986): 20.

${ }^{46}$ En Calderón, Fernando (Coord.), ¿Es posible la globalización en América Latina? Debate con Manuel Castells. Tomo I. Fondo de Cultura Económica, 2004.
} 
cambios sociales y culturales- como ciudadanos-consumidores, integrados al mercado a partir del endeudamiento y la enajenación ${ }^{47}$. Acerca de la situación indígena continental, se sostiene que la población en número asciende a poco más de 40 millones de personas; junto a esto, de acuerdo a analistas variopinto, los indígenas después de una década agitada y "en movimiento" son hoy por hoy reconocidos, por primera vez en su historia, como sujetos sociales y sujetos políticos, lo que implica ser un agente distinguible en las estructuras de poder, los debates y la construcción de conocimiento social ${ }^{48}$.

En este escenario global ¿De qué trató el proceso de debate y construcción de conocimiento étnico social? En varios casos, los estudios intelectuales se fueron entretejiendo a partir de intereses políticos; es el caso emblemático de Bolivia y la figura de Evo Morales como indígena-presidente; además se enfatizó en el rescate de los saberes ancestrales y comunitarios, la interculturalidad como herramienta de nuevo trato y el estudio de los discursos indígenas, entre otros. Consideremos en este punto, el año 2005 en Chile se llevó a cabo un Seminario internacional que congregó a intelectuales indígenas de todo el continente, actas que fueron públicas bajo la coordinación de la investigadora Claudia Zapata, el año 2007 con apoyo de la Universidad Simón Bolívar de Ecuador ${ }^{49}$; sosteniendo que el objetivo del libro fue "[...] visibilizar a este intelectual indígena reciente, que accedió a la educación superior, se formó en una disciplina, que investiga y ve en este trabajo un insumo para la rearticulación política de sus pueblos" 50 .

Si nos enfocamos históricamente en los interés políticos, la discusión diacrónica centró su afán en categorías analíticas tales como Estado pluricultural y multiétnico, diversidad y movimientismo preferentemente. En este sentido, el historiador mapuche Víctor Toledo Llancaqueo ha presentado una visión histórica panorámica y estrategia de la situación de los movimientos indígenas regionales. Según este autor, estos movimientos desde 1990 en adelante han vivido dos grandes etapas, la primer comprendida entre el año antes mencionado y el año 2003, tiempo propicio para los etnomovimientos y sus reivindicaciones, y otro ciclo iniciado en los primeros años de la década de 2000, el cual se ha puesto cuesta arriba para los movimientos indígenas, toda vez que los Estados han profundizado las políticas de mercado, cuestión que ha afectado directamente a las comunidades indígenas de toda la región ${ }^{51}$. El choque Estados - transnacionales versus pueblos indígenas ha comenzado a registrar grandes fricciones ${ }^{52}$. En este sentido, Antonio Pérez reconoce en la obra de Ayar Quispe, publicada en mayo de 2012 con el nombre de Indianismo, un libro serio, evaluativo y propositivo, que aborda esta coyuntura, describiendo conflictos y controversias entre las partes ${ }^{53}$.

\footnotetext{
${ }^{47}$ García Canclini, Néstor. Consumidores y Ciudadanos. España: Editorial Grijalbo, (1995): 8.

${ }^{48}$ Dávalos, Pablo. "De paja de páramo, sembraremos al mundo: Izquierda, utopía y movimiento indígena en Ecuador". En César Rodríguez Gaviro, Patrick S. Barrett y Daniel Chavez (Eds.), La nueva izquierda en América Latina. Sus orígenes y trayectoria futura. Colombia: Grupo editorial Norma, (2005): 359-404; Toledo Llancaqueo, Víctor. Pueblo Mapuche, derechos colectivos y territorio: Desafios para la sustentabilidad. Santiago de Chile: Ediciones LOM, (2006): 7.

${ }^{49}$ Zapata, Claudia. Los intelectuales... op. cit.

${ }^{50}$ Ibid., 11.

${ }^{51}$ Toledo Llancaqueo, Víctor. “Políticas indígenas y derechos territoriales en América Latina: 1990-2004”. En Pablo Dávalos

y Víctor Toledo. Pueblos indigenas en América Latina. Argentina: CLACSO, 2006.

${ }^{52}$ Ibid.

${ }^{53}$ Pérez, Antonio. Entrevista realizada el 19 de noviembre de 2011.
} 
En cuando al rescate de los saberes ancestrales y comunitarios, la intelectualidad étnica fue precisando aspectos centrales de la discusión. Por ejemplo, Luís Macas en Ecuador ha sostenido que el reposicionamiento de los saberes ancestrales es la llave para la pervivencia de los pueblos y nacionalidades indígenas ${ }^{54}$, cuestión que se suma al anhelo de un grupo de historiadores mapuche en Chile, liderados por Pablo Marimán, los cuales llaman a crear una nueva epistemología desde lo indígena ${ }^{55}$. En esta misma línea, Irma Velásquez de Guatemala, plantea que el Estado "[...] ha dado derechos culturales pero sigue negando derechos históricos, de reparación, espirituales y económicos a los pueblos indígenas" 56 .

Otros trabajos y discusiones vinculados al rescate de los saberes ancestrales y comunitarios, los vemos en proposiciones como las de María Eugenia Choque y Simón Yampara, cuando se internan en la reconstrucción de los ayllu y los derechos indígenas, o con trabajos como los de Roberto Choque ligados al relato de historias de luchas desiguales. En esta misma senda, Pedro Portugal por medio de artículos y su diario Pukara, en circulación en Bolivia desde 2005, presenta una interesante propuesta o espacio para el debate y conocimiento de los saberes antiguos y propios de la comunidad histórica ${ }^{57}$.

En virtud de lo anterior, de la historia indígena y los anhelos de su intelectualidad de escribir "su propia historia", podemos mencionar como texto clave para aprehender esta época, el libro de cuatro historiadores mapuche, denominado Escucha, winka, publicado en Chile el año 2006. En él se presentan cuatro ensayos de historia nacional mapuche, como indican sus autores y una propuesta de futuro ${ }^{58}$. Sin duda que este es el esfuerzo más trascendental de rescate y apropiación académica de la etnohistoria entre intelectuales indígenas en Chile. Antes, el año 2002, José Ankáń reeditó un texto de Tomás Guevara acerca de las familias mapuche de 1910. Lo interesante y reparador de este texto, es que el autor de la reedición, reivindica la coautoría negada en el texto original a un intelectual mapuche, el profesor y político Manuel Manquilef ${ }^{59}$, ejemplificando así la orientación del trabajo intelectual descolonizador de dichos años. Ahora bien, resulta interesante constatar que ese mismo año, el 2002, se llevó a cabo en Alemania el primer congreso de historia mapuche, coordinado por Carlos Contreras Painemal, y al cual concurrió un selecto grupo de historiadores de este pueblo ${ }^{60}$.

El año 2012 el debate y proceso de producción de conocimiento entre los mapuche en Chile, ha ido cerrado un ciclo y abierto otro, con la publicación de los libros Autoderminación de José Marimán ${ }^{61}$ y el autogestionado por la Comunidad de historia mapuche ${ }^{62}$ titulado Ta in fijke xipa rakizuameluwün (Historia, colonialismo y resistencia desde el país Mapuche $)^{63}$, ambos textos asumen posturas críticas respecto de la alteridad y las proyecciones de las reivindicaciones mapuche como pueblo y cultura.

\footnotetext{
${ }^{54}$ Macas, Luis. "La necesidad política de una reconstrucción epistémica de saberes ancestrales”. En Pablo Dávalos (Comp.), Pueblos Indigenas, Estado y Democracia. Argentina: CLACSO, 2005.

${ }^{55}$ Marimán, Pablo et al. j...Escucha, winka...! op. cit.

${ }^{56}$ Velásquez, Irma. Entrevista realizada el 26 de marzo de 2012.

${ }^{57}$ Véase en: http://www.periodicopukara.com/archivos/pukara-46.pdf

${ }^{58}$ Marimán, Pablo et al. j...Escucha, winka...! op. cit.

${ }^{59}$ Guevara, Tomás y Manquilef, Manuel. Familias mapuche (re-edición). Santiago de Chile: Ediciones LOM, 2002.

${ }^{60}$ Actas Primer Congreso de historia mapuche, Alemania, 2002.

${ }^{61}$ Marimán, José. Autodeterminación. Santiago de Chile: Ediciones LOM, 2012.

${ }^{62}$ Comunidad de Historia Mapuche (CHM): agrupación de historiadores/as Mapuche que se ha organizado con el fin de producir conocimiento etnosocial desde las esferas de lo propio.

${ }^{63}$ Libro titulado Ta in fijke xipa rakizuameluwün. Historia, colonialismo y resistencia desde el país Mapuche. Santiago de Chile, 2012.
} 
Por último, desde la esfera educacional, la lingüística y la interculturalidad siguieron siendo un punto central durante esta década, comenzando a ser vistas como herramientas descolonialista, en el más amplio sentido de la palabra, por los intelectuales indígenas. El año 2001 Felipe Huayhua en Lima -por ejemplo- publicó una gramática descriptiva de la lengua aymara ${ }^{64}$; ese mismo ańo Elías Ticona profundizó en las competencias lingüísticas de los hablantes aymaras en el norte chileno. $\mathrm{Al}$ ańo siguiente, estas propuestas se reprodujeron, deteniendo la mirada en elementos gramaticales nuevamente, tal como lo indica Félix Layme ${ }^{65}$, o el propio Ticona junto a Pedro García al presentar un diccionario didáctico de la lengua aymara ${ }^{66}$, a lo que Natalio Hernández del México complementa con su obra El despertar de nuestra lengua, publicada en $2002^{67}$. En palabras de la lingüista Elisa Loncón, la situación de los pueblos indígenas y sus lenguas es dramática, lo que hace urgente congregar voluntades y expandir la enseñanza de las lenguas entre indígenas y no indígenas. Según esta experta, hoy lo importante es que la sociedad aprenda los idiomas indígenas, de lo contrario morirán en el olvido ${ }^{68}$.

\section{CONCLUSIÓN}

Podemos comenzar este cierre, consignando que la intelectualidad indígena en Latinoamérica ha sido un creciente interlocutor en el diálogo -cuando existe claro está- entre las esferas del poder público estatal, la sociedad civil en general y los pueblos indígenas de la región. En gran medida el creciente peso de estos sujetos, ha sido explicado en las líneas precedentes.

La intelectualidad referida comenzó a interpelar al modelo de dominación republicano, altamente colonialistas en sus formas y símbolos, aun después de 200 años de iniciados los procesos emancipatorios en esta parte del mundo. Si bien la Hacienda, paradigma de este orden nuevo-antiguo podríamos decir, contradictorio en el más amplios sentido de la palabra, dejó de existir hace décadas en las historias nacionales, resulta decidor dejar en claro que la mentalidad colonialista no ha cesado de enhebrar su ropaje.

¿Qué hizo entonces que jóvenes estudiantes indígenas se comenzaran a sacudir del ropaje de dominación propio de repúblicas que miraron al nacer hacia Europa como ejemplo a seguir? Si bien, como han establecido Juan Nanculef y Cornelio Chipana, los pueblos indígenas tienen sus propios códigos de sabiduría, conocimiento y cuadros dedicados a preservar y difundir estos elementos, no es menos cierto que los profesionales indígenas que lograr ingresar a espacios educativos, de los años 80 fueron "hombres de su tiempo" en cuanto defendieron a sus pueblos, comunidades y territorios, pero no cuestionaron radicalmente el discurso hegemónico de asimilación y absorción étnicocultural que las esferas del poder, apoyadas por el indigenismos estatal post Pátzcuaro,

\footnotetext{
${ }^{64}$ Huayhua, Felipe. Gramática descriptiva de la lengua aymara. Lima: Instituto de reafirmación de los pueblos Aimaras, Quechuas y Amazonenses, 2001.

${ }^{65}$ Navega Félix, Igido. Evaluación del proyecto institucional del CONAMAQ. Lima: Oxfam-América, 2003.

${ }^{66}$ Ticona, Elías y García, Pedro. Introducción general a la lengua aymara. Breve Diccionario Aru Pirwa Aymara-Castellano/ Castellano-Aymara. Iquique: Ediciones Instituto de Estudios Andinos, Universidad Arturo Prat. 13-24.

${ }^{67}$ Hernández, Natalio. El despertar de nuestras lenguas. México: Diana-Fondo Editorial de Culturas Indígenas, 2002.

${ }^{68}$ Loncón, Elisa. Entrevista del autor realizada el 26 de marzo de 2012.
} 
consolidaron en toda la región. Como indicó el presidente de México, Lázaro Cárdenas, al momento de inaugurar el Io Congreso Indigenista de la región en 1940, había que mexicanizar a los indios.

El proceso decolonial entre los y las intelectuales indígenas en los diferentes territorios de Abya Yala, nació a partir de la descomposición del antiguo orden hacendal y su triada del terror, en palabra de Braulio Muñoz: el patrón, el policía y el sacerdote. Pero esto no bastó. Fue necesaria una estructura de oportunidades políticas marcada por contextos políticos, sociales, económicos y culturales: las dictaduras militares y posteriores procesos redemocratizadores, ampliaron los márgenes de la participación social en proyectos de inclusión y establecieron las pautas para un nuevo trato entre bandos diversos, en el cual los derechos humanos pasaron a ser preponderantes en las intenciones de unos y otros; por otro lado, las nuevas políticas económicas fueron abriendo al mundo los territorios y recursos naturales ubicados en zonas indígenas, lo que activó el discurso de resistencia y lucha de estos pueblos; en las grandes ciudades, la visibilización indígena y la imagen de gesta y epopeya trasuntado por los movimientos contra las trasnacionales y sus mega proyectos extraccionistas, fueron activando verdaderos procesos de reetnificación o etnogénesis, especialmente entre jóvenes urbanos indígenas.

Los "viejos" movimientos indígenas, aquellos de corte gremialista y defensores de la cultura y el derecho a la educación de los niños indígenas, fue dando paso a otro tipo de movimiento, mucho más horizontal y diverso, más conectado con la realidad propia de la alteridad. En este contexto, la intelectualidad indígena comenzó a expresarse y proponer.

\section{REFERENCIAS}

Alburquerque, Germán. "La trinchera letrada. Ideas, acción y poder del intelectual latinoamericano en la Guerra Fría”. Tesis doctoral. Santiago de Chile: Pontificia Universidad Católica de Chile, 2009.

Ankañ, José. "Los urbanos: Un nuevo sector dentro dela sociedad mapuche contemporánea”, Pentukun 1. Temuco, Chile: Instituto de Estudios Indígenas, Universidad de la Frontera, 1994.

Ankañ, José y Calfío, Margarita. "El retorno al país Mapuche", Revista Liwen 5. CEDM Liwen. Temuco, Chile, 1999.

Assies, Willem y Gundermann, Hans (Edit.), Movimientos indigenas y gobiernos locales en América Latina. San Pedro de Atacama: Línea Editorial IIAM - Universidad Católica del Norte, 2007.

Beck, Ulrich. La sociedad del riesgo. Hacia una nueva modernidad. Barcelona: Editorial Paidós, 1986. 
Bello, Álvaro."Intelectuales indígenas y universidad en Chile: conocimiento, diferencia y poder entre los mapuche en Robert Austin". En Robert Austin (Ed.), Intelectuales y Educación Superior en Chile: De la Independencia a la Transición Democrática 1810-2001. Santiago de Chile: Editorial CESOC, 2004.

Bengoa, José. Emergencia indígena en América Latina. Santiago de Chile: Fondo de Cultura Económica, 2000.

----------.. Emergencia indígena en América Latina. Santiago de Chile: Fondo de Cultura Económica, 1999.

Historia de un conflicto: El estado y los mapuches en el siglo XX. Santiago de Chile: Editorial Planeta, (1999): 183-215.

Calderón, Fernando (Coord.), ¿Es posible la globalización en América Latina? Debate con Manuel Castells. Tomo I. Fondo de Cultura Económica, 2004.

Canales, Pedro. “Impronta 79”, Revista Pentukun 3. IEI. UFRO, 1998.

Castells, Manuel. La era de la información. Economía, sociedad y política. El poder de la identidad. Volumen II. México: Siglo XXI Editores, 2002.

Catrileo, María. "Consideraciones lingüísticas en torno a un grafemario uniforme para el mapudungun”, Actas de Lengua y Literatura 1. Temuco: UFRO, 1995.

-. "Conceptos y formas de cuantificación en el mapudungun", Revista de Lingüistica Teórica y Aplicada 23. Concepción, Chile: Universidad de Concepción, 1995.

Chipana, Cornelio. "La universidad y los pueblos indígenas, mito y realidad". En José Aylwin (Edit.), Universidad y pueblos indigenas. Temuco, Chile: Instituto de Estudios Indígenas, Universidad de la Frontera, 1997.

Choque, Roberto. La masacre de Jesús de Machaca. Bolivia: Ediciones Chitakolla, 1986.

CONAIE. Las nacionalidades indigenas en el Ecuador. Nuestro proceso organizativo. Quito: Ediciones Abya Yala, 1989.

Dávalos, Pablo. "Movimiento indígena en América Latina: el derecho de la palabra". En Pablo Dávalos (Comp.), Pueblos Indigenas, Estados y Democracia. Argentina: CLACSO, 2005.

."De paja de páramo, sembraremos al mundo: Izquierda, utopía y movimiento indígena en Ecuador”. En César Rodríguez Gaviro, Patrick S. Barrett y Daniel Chavez (Eds.), La nueva izquierda en América Latina. Sus orígenes y trayectoria futura. Colombia: Grupo editorial Norma, (2005): 359-404. 
De La Cruz, Víctor. "La escritura contemporánea del zapoteca del Istmo”. En Claudia Zapata (Comp.), Intelectuales indígenas piensan América Latina. Serie Tinkuy No 2, Universidad Andina Simón Bolívar - Centro de Estudios Culturales Latinoamericanos de la Universidad de Chile - Editorial Abya Yala, Quito, (2007): 129-150.

Devés, Eduardo. Carta a la intelectualidad. Santiago de Chile: Grafitti Editores, 2007.

Di Pascuale, Mariano. "De la historia de las ideas a la nueva historia intelectual: Retrospectivas y perspectivas. Un mapeo de la cuestión”, Universum. Revista de Humanidades y Ciencias Sociales 26/1, 2011.

Fernández, Blanca. “¿Quiénes son los intelectuales indígenas ecuatorianos? Aportes para la construcción intercultural de saberes en América Latina”, A Parte Rei. Revista de Filosofia 71, 2010.

García Canclini, Néstor. Consumidores y Ciudadanos. España: Editorial Grijalbo, 1995.

Gómez Leyton, Juan Carlos. Chile Neoliberal. Editorial Universidad ARCIS - CLACSO Ediciones, 2010.

Guevara, Tomás y Manquilef, Manuel. Familias mapuche (re-edición). Santiago de Chile: Ediciones LOM, 2002.

Hernández, Natalio. El despertar de nuestras lenguas. México: Diana-Fondo Editorial de Culturas Indígenas, 2002.

Huayhua, Felipe. Gramática descriptiva de la lengua aymara. Lima: Instituto de reafirmación de los pueblos Aimaras, Quechuas y Amazonenses, 2001.

Humire, Pedro. "Influencia de la cultura occidental en la desaparición de la lengua aymara en el norte de Chile", Antropología histórica. Etnología contemporánea. Anales de la reunión anual de etnología. Tomo 1. La paz, Bolivia: USEF, 1986.

Loncón, Elisa. Por una nueva política del lenguaje. Temas y estrategias del desarrollo lingüistico del mapudungun. Temuco, chile: Pehuén - UFRO, 1995.

Macas, Luis. Cartillas 1, 2, 3 de Alfabetización de Adultos "Nucanchi Shimi". Ecuador: Publicación de la Pontificia Universidad Católica del Ecuador y del Ministerio de Educación y Cultura, 1980.

Metodología de Enseñanza para maestros. Quito: Pontificia Universidad Católica del Ecuador, 1982. 
Experiencias de Educación Bilingüe de América Latina. México: Instituto Indigenista Interamericano y la UNESCO, 1984.

- "La necesidad política de una reconstrucción epistémica de saberes ancestrales”. En Pablo Dávalos (Comp.), Pueblos Indígenas, Estado y Democracia. Argentina: CLACSO, 2005.

Marimán, Pablo; Caniuqueo, Sergio; Millalén, José y Levil, Rodrigo. j...Escucha, winka...! Cuatro ensayos de Historia Nacional Mapuche y un epilogo sobre el futuro. Santiago de Chile: LOM Ediciones, 2006.

Marimán, Pablo. "Formación de intelectuales indígenas: ¿El rol de la educación superior?” Ponencia presentada en Congreso Internacional "Equidad, Interculturalidad y Educación superior". Chile, Temuco, 2011.

Marimán, José. Autodeterminación. Santiago de Chile: Ediciones LOM, 2012.

Martí, Salvador. Sobre la emergencia e impacto de los movimientos indígenas en las arenas politicas de América Latina. Barcelona: CIDOB, 2004.

Monroy-Álvarez, Silvia. "Sobre intelectuales y activistas indígenas: Dos trayectorias interculturales posibles", Universitas humanistica 66, 2008.

Navega Félix, Igido. Evaluación del proyecto institucional del CONAMAQ. Lima: OxfamAmérica, 2003.

Ocampo, Juan Antonio. América Latina y el Caribe. CEPAL, 2005; French-Davis, Ricardo. Reformas para América Latina. Después del fundamentalismo Neoliberal. Argentina: CEPAL - Siglo XXI Editores, 2005.

Panchillo, María Teresa y Ancamil, Ximena. Amulepe tayiñ mogen: Que nuestra vida continué. Comité de solidaridad catalán. Temuco, Chile. S/F/E.

Quinatoa, Estelina. Textiles de Alejandro Quinatoa. Catálogo de exposición. Quito: Banco Central del Ecuador - OEA.

Raguileo, Anselmo. "El alfabeto mapuche", Boletin informativo desarrollo y cambio No 2. Temuco: CAPIDE, 1982.

."Tres modos de hablar el Mapudungun", Boletín informativo desarrollo y cambio No 14. Temuco: CAPIDE, 1985.

. "Construcción analítica y construcción sistemática en el Mapudungun", Boletín informativo desarrollo y cambio No 16. Temuco: CAPIDE, 1985. 
Rama, Ángel. La ciudad letrada. Santiago de Chile: Tajamar Ediciones, 2004.

Rappaport, Joanne. "Intelectuales públicos indígenas en América latina: Una aproximación comparativa", Revista Iberoamericana 220, 2007.

Ticona, Elías y García, Pedro. Introducción general a la lengua aymara. Breve Diccionario Aru Pirwa Aymara-Castellano/Castellano-Aymara. Iquique: Ediciones Instituto de Estudios Andinos, Universidad Arturo Prat. 13-24.

Toledo Llancaqueo, Víctor. Pueblo Mapuche, derechos colectivos y territorio: Desafios para la sustentabilidad. Santiago de Chile: Ediciones LOM, 2006.

----------.- "Políticas indígenas y derechos territoriales en América Latina: 19902004”. En Pablo Dávalos y Víctor Toledo. Pueblos indígenas en América Latina. Argentina: CLACSO, 2006.

Viaña, Jorge. La interculturalidad como herramienta de emancipación. La Paz, Bolivia: Instituto internacional de integración. Convenio Andrés Bello, (2009): 20.

Zapata, Claudia (Comp.), Intelectuales indigenas piensan América Latina. Serie Tinkuy No 2, Universidad Andina Simón Bolívar - Centro de Estudios Culturales Latinoamericanos de la Universidad de Chile - Editorial Abya Yala, Quito, 2007. 